\title{
SINTESIS DAN UJI FTIR BARIUM M-HEXAFERRITE DENGAN DOPING LOGAM Mn
}

\author{
Aris Doyan, Khalilurrahman, Susilawati \\ Program Studi Magister Pendidikan IPA \\ Program Pascasarjana Universitas Mataram \\ Mataram, Indonesia. \\ Email: arisdoyan@yahoo.com
}

\begin{abstract}
Has successed studied shyntesis Barium M-Hexaferrite (BaM) powder with doping Mn and tested using Fourier Transform Infrared (FTIR). Shyntesis has using coprecipitation method. This study intend to describe substitute $\mathrm{Mn}$ against crystal bounded of BaM process with $\mathrm{x}=0 ; 0.2 ; 0.4$; and 0.6. BaM powder with doping $\mathrm{Mn}$ is dried on themperature $80{ }^{\circ} \mathrm{C}$ and calcined on themperature $400 ; 600$; and $800{ }^{\circ} \mathrm{C}$ for 4 hours. Barium M-Hexaferrite $\mathrm{BaFe}_{12-\mathrm{x}} \mathrm{Mn}_{\mathrm{x}} \mathrm{O}_{19}$ doped by $\mathrm{Mn}$ characterized using FTIR. The result show that wave number between 450 until $690 \mathrm{~cm}^{-1}$ is metal bound (Fe-O) on BaM phase and range between 1000 until 1650 $\mathrm{cm}^{-1}$ showing characteristic of $\mathrm{Ba}-\mathrm{O}$ bound.
\end{abstract}

Keywords : Shyntesis, Barium M-Hexaferrite, Coprecipitation, FTIR

\section{Pendahuluan}

Penelitian menunjukkan bahwa material magnet dapat digunakan untuk pengurangan intensitas gelombang pantul pada radar terhadap suatu obyek yang biasa disebut dengan Radar Cross Section (RCS) yang dimanfaatkan dalam aplikasi pada pesawat atau perangkat militer untuk menghindari deteksi. Material ini biasa dikenal dengan Radar Absorbing Material (RAM). Material Radar Absorbing Material (RAM) digolongkan menjadi dua yaitu material dari bahan dielektrik dan material dari bahan magnetik. Material dari bahan magnetik yang sedang banyak dikembangkan adalah Barium M-Hexaferrite (BaM). Unsur besi penyusun $\mathrm{BaM}$ dapat diganti dengan kation logam lain dari golongan transisi yang memiliki ukuran yang hampir sama seperti $\mathrm{Co}, \mathrm{Zn}, \mathrm{Ni}$, dan $\mathrm{Mn}^{[1]}$

Penelitian ini mengkonsentrasikan pembentukan fasa komposit paduan antara $\mathrm{BaFe}_{12} \mathrm{O}_{19}$ yang disubstitusi logam Mn dengan variabel nilai $\mathrm{x}=0 ; 0,2$; 0,4 ; dan 0,6 serta dengan kalsinasi pada suhu 400,600, dan $800{ }^{\circ} \mathrm{C}$ yang diharapkan mampu menghasilkan material magnet dengan sifat listrik dan magnet yang berpotensi sebagai bahan anti radar.

\section{TinJAUAn PUSTaka}

Ferrimagnetik oksida atau yang biasa disebut ferrite, adalah bahan keramik ferrimagnetik berwarna coklat tua atau abu-abu, sangat keras dan rapuh.Struktur kristal sangat kompleks, tetapi hal itu dapat digambarkan dengan struktur Kristal berbentuk heksagonal dengan sumbu c $(0,01)$ yang unik, yang merupakan sumbu yang mudah termagnetisasi dalam struktur dasar ${ }^{[2]}$.

Barium M-Hexaferrite sering ditulis dengan notasi $\mathrm{BaM}$ dan memiliki stoikiometri dengan struktur hexagonal yang mantap yang merupakan feromagnetik oksida dengan sifat dielektrik dan magnetik yang banyak digunakan pada aplikasi RF (Radio Frequency) dan microwave. Penggunaan BaM sebagai material magnet permanen dan perekam magnetik sangat diminati sehingga banyak penelitian dilakukan pada jenis material ini.

Berbagai sifat magnetik material dapat divariasi dengan substitusi pada kation yang berisi unsur besi $\mathrm{Fe}^{+3}$ dalam $\mathrm{BaFe}_{12} \mathrm{O}_{19}$. Divalen logam transisi seperti $\mathrm{Ni}, \mathrm{Co}, \mathrm{Mn}, \mathrm{Cr}$, Ti sering digunakan karena memilki persamaan jari-jari ionik dan konfigurasi elektron. Sifat kelistrikan dan kemagnetan dari substitusi BaM sangat bergantung pada kondisi sintesisnya karena disebabkan oleh ketidaksebandingan distribusi muatan pada proses substitusi multivalen kationnya ${ }^{[3]}$.

Berdasarkan rumus kimia dan struktur kristalnya, barium hexaferrite dikelompokkan menjadi 6 tipe yaitu $\mathrm{M}\left(\mathrm{BaFe}_{12} \mathrm{O}_{19}\right), \mathrm{Y}\left(\mathrm{BaMe}_{2} \mathrm{Fe}_{12} \mathrm{O}_{22}\right), \mathrm{W}$ $\left(\mathrm{BaMe}_{2} \mathrm{Fe}_{16} \mathrm{O}_{27}\right), \quad \mathrm{Z} \quad\left(\mathrm{Ba}_{3} \mathrm{Me}_{2} \mathrm{Fe}_{24} \mathrm{O}_{41}\right), \quad \mathrm{X}$ $\left(\mathrm{Ba}_{2} \mathrm{Me}_{2} \mathrm{Fe}_{28} \mathrm{O}_{46}\right)$ dan $\mathrm{U}\left(\mathrm{Ba}_{4} \mathrm{Me}_{2} \mathrm{Fe}_{36} \mathrm{O}_{60}\right)^{[4]}$. M, Y, W, $\mathrm{Z}, \mathrm{X}$, dan $\mathrm{U}$ menyatakan tipe dari barium hexaferrite yang ditentukan oleh jumlah kandungan ion besi dan oksigen dalam senyawa. Sedangkan Me menyatakan suatu variabel yang bisa diganti dengan ion $\mathrm{Zn}, \mathrm{Ti}, \mathrm{Co}$, $\mathrm{Ga}, \mathrm{Al}$, serta kation logam lainnya yang ukurannya hampir sama sesuai dengan sifat yang ingin dimunculkan. Hexagonal ferrite memiliki resistivitas, anisotropik magnetokristalin, dan magnetisasi saturasi yang tinggi, serta tegangan hilang dielektrik yang rendah pada stabilitas termal ${ }^{[5]}$.

Menurut Ahmeda, dkk. (2008), pembedaan tipe struktur barium hexaferrite didasarkan pada superposisi sepanjang sumbu c (sumbu $0,0,1$ ) yang ditandai dengan blok T, R, dan $S$, seperti RSR*S*S* untuk tipe X, TSTSTS untuk tipe Y, RSTSR*S*T*S* untuk tipe Z, RSSR $* S * S *$ untuk tipe $\mathrm{W}, \mathrm{RSR} * \mathrm{~S} * \mathrm{~T} * \mathrm{~S} *$ 
untuk tipe $\mathrm{U}$, dan RSR*S* untuk tipe M. Dimana T merupakan sebuah lapisan 4 ion oksigen $\left(\mathrm{O}_{4}-\mathrm{BaO}_{3}-\right.$ $\left.\mathrm{BaO}_{3}-\mathrm{O}_{4}\right)$ dengan komposisi senyawa $\mathrm{Ba}_{2} \mathrm{Fe}_{8} \mathrm{O}_{14}$ dan $\mathrm{R}$ adalah blok 3 lapis $\left(\mathrm{O}_{4}-\mathrm{BaO}_{3}-\mathrm{O}_{4}\right)$ dengan komposisi senyawa $\mathrm{BaFe}_{6} \mathrm{O}_{11}{ }^{2-}$ dan $\mathrm{S}$ adalah blok 2 lapisan oksigen $\left(\mathrm{O}_{4}-\mathrm{O}_{4}\right)$ dengan komposisi $\mathrm{Fe}_{6} \mathrm{O}_{8}{ }^{2+}$. Adanya rumus kimia dan struktur kristal yang berbeda dari masing-masing tipe barium hexaferrite tentunya akan menghasilkan pola difraksi yang berbeda. Hexagonal ferrite dengan struktur magnetoplumbite sejak lama telah menarik perhatian peneliti. Nilai anisotropi magnetokristalin dan magnetisasi saturasi yang tinggi menjamin aplikasi ini. Struktur kristal yang paling banyak diteliti adalah $\mathrm{BaFe}_{12} \mathrm{O}_{19}$ dengan space group $\mathrm{P} 63 / \mathrm{mmc}^{[6]}$. Struktur kristalini adalah heksagonal dengan parameter kisi $\mathrm{a}=\mathrm{b}=5,892 \AA, \mathrm{c}=23,183 \AA$, $\alpha=\beta=90^{\circ}, \gamma=120^{\circ}$ dengan kode database 1008841 mengacu pada data crystallographic information file (CIF) $\mathrm{BaFe}_{12} \mathrm{O}_{19}$.

\section{Metode Penelitian}

BaM dengan doping logam $\mathrm{Mn}$ disintesis menggunakan metode kopresipitasi dengan konsentrasi nilai $\mathrm{x}$ yang bervariasi. Metode kopresipitasi adalah metode pengendapan dengan menggunakan lebih dari satu substansi yang diendapkan secara bersama-sama dengan penambahan suatu pengendap. Pada penelitian ini, pengendap yang digunakan $\mathrm{NH}_{4} \mathrm{OH} \mathrm{M}=6,5 \mathrm{M}$.

Material dasar dalam pembuatan serbuk BaM dengan doping logam $\mathrm{Mn}$ yang digunakan antara lain $\mathrm{BaCO}_{3}$, dan $\mathrm{FeCl}_{3} \cdot 6 \mathrm{H}_{2} \mathrm{O}$ sebagai bahan dasar dan $\mathrm{MnCl}_{2} \cdot 4 \mathrm{H}_{2} \mathrm{O}$ sebagai material dopan dengan variasi nilai x $0 ; 0,2 ; 0,4$ dan 0,6 . Pembuatan material serbuk $\mathrm{BaM}$ dilakukan dengan metode kopresipitasi. Adapun langkah-langkah pembuatan material $\mathrm{BaM}$ dengan rumus kimia $\mathrm{BaFe}_{12-\mathrm{x}} \mathrm{Mn}_{\mathrm{x}} \mathrm{O}_{19}$ ini diawali dengan melarutkan $\mathrm{BaCO}_{3}$ dengan $\mathrm{HCl}$ dan $\mathrm{H}_{2} \mathrm{O}$ dengan menggunakan hot plate dengan suhu $70-80^{\circ} \mathrm{C}$ selama 2 jam sehingga dihasilkan larutan $\mathrm{BaCl}_{2}$ yang homogen. Langkah selanjutnya melarutkan $\mathrm{FeCl}_{3} .6 \mathrm{H}_{2} \mathrm{Odengan} \mathrm{H}_{2} \mathrm{O}$ menggunakan magnetic stirrer dan menghasilkan larutan $\mathrm{FeCl}_{3}$ yang homogen ${ }^{[7]}$. Langkah berikutnya melarutkan $\mathrm{MnCl}_{2} .4 \mathrm{H}_{2} \mathrm{O}$ dengan $\mathrm{H}_{2} \mathrm{O}$ sehingga dihasilkan larutan $\mathrm{MnCl}_{2}$ yang homogen. Selanjutnya mencampur larutan $\mathrm{BaCl}_{2}, \mathrm{FeCl}_{3}$ dan larutan $\mathrm{MnCl}_{2}$ ke dalam satu wadah sehingga terbentuk larutan $\mathrm{BaFe}_{12-\mathrm{x}} \mathrm{Mn}_{\mathrm{x}} \mathrm{O}_{19}$ berwarna coklat. Selanjutnya mentitrasi larutan $\mathrm{BaFe}_{12-\mathrm{x}} \mathrm{Mn}_{\mathrm{x}} \mathrm{O}_{19}$ dengan $\mathrm{NH}_{4} \mathrm{OH}$ (konsentrasi $6,5 \mathrm{M}$, PA 99,9\% dan Volume 52,557 ml) sampai $\mathrm{pH}$ larutan asam lemah dan terjadi pengendapan. Setelah diperoleh endapan, bahan kemudian disaring dengan menggunakan kertas saring dan dicuci dengan aquades sampai $\mathrm{pH}$ 7. Selanjutnya pengeringan dilakukan pada temperatur $80{ }^{\circ} \mathrm{C}$. Selanjutnya proses penggerusan sehingga diperoleh bahan yang sangat halus dan dikalsinasi dengan suhu yang bervariasi yaitu 400, 600 dan $800^{\circ} \mathrm{C}$ selama 4 jam. Tahapan selanjutnya yakni melakukan pengujian FTIR. Berikut ini gambar diagram alir pembuatan serbuk BaM dengan doping logam Mn :

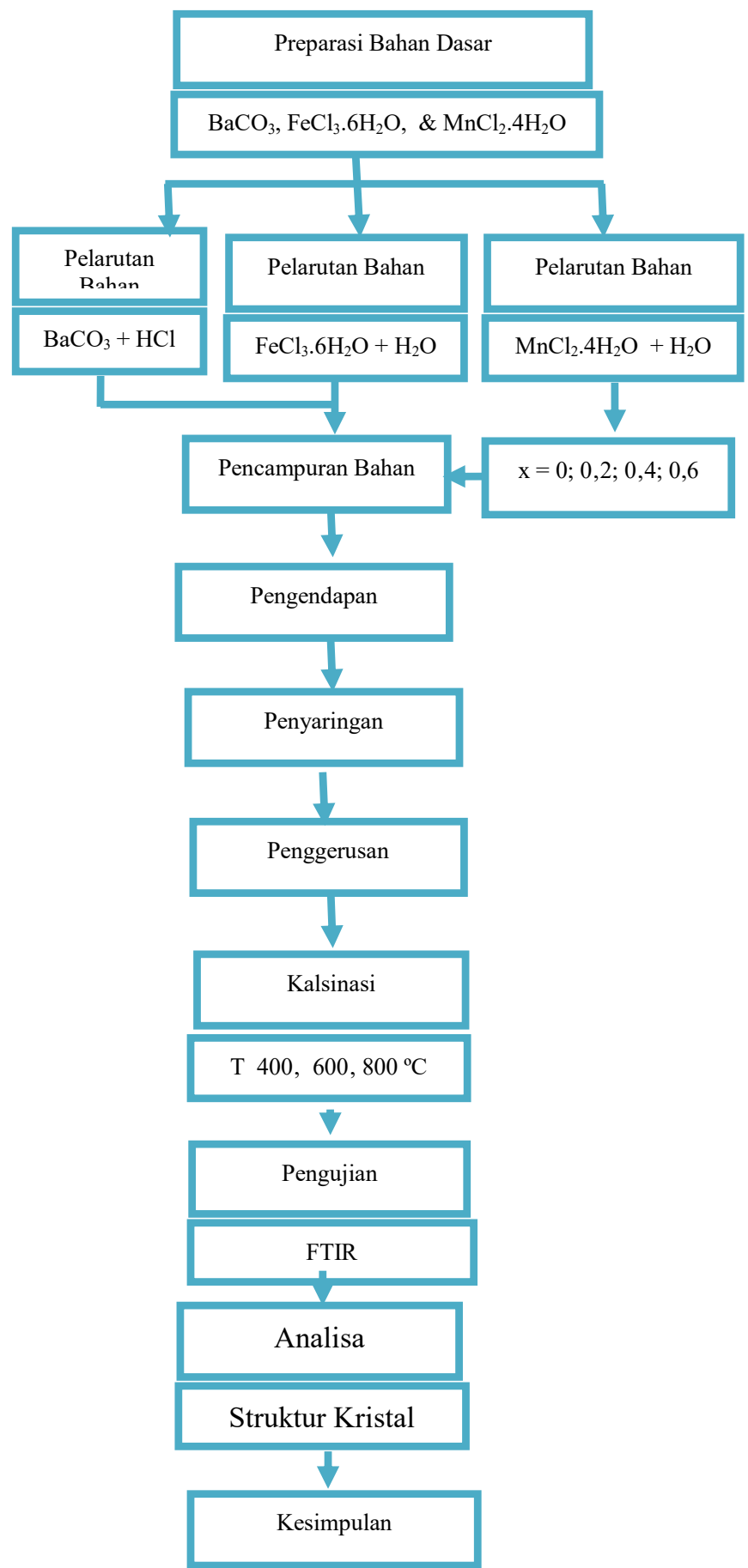

Gambar 1. Diagram alir pembuatan BaM dengan doping logam Mn dan pengujian menggunakan FTI.

\section{Hasil dan Pembahasan}

\section{A. Hasil Penelitian}

Sintesis BaM dengan doping logam Mn menghasilkan serbuk berwarna kecoklatan. Berikut gambar hasil sintesis BaM dengan doping logam Mn : 
$\mathrm{T}\left({ }^{0} \mathrm{C}\right)$

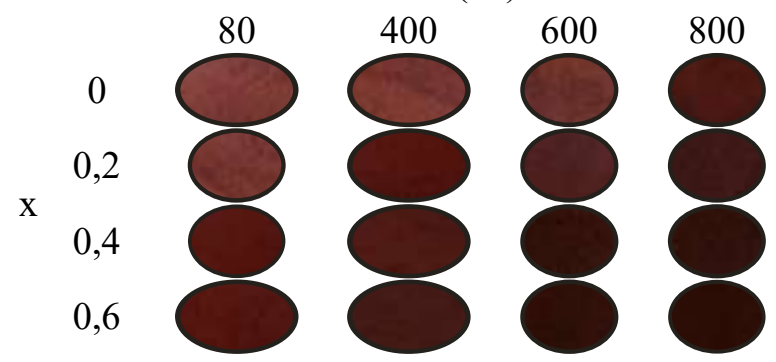

Gambar 2. Hasil sintesis serbuk BaM dengan berbagai variasi $\mathrm{x}$ doping logam $\mathrm{Mn}$ dan temperatur kalsinasi.

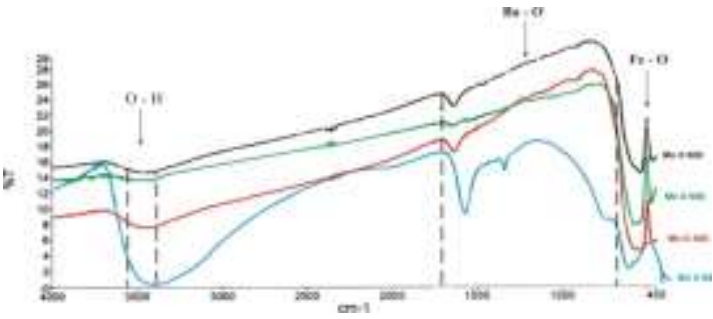

(a) $x=0$

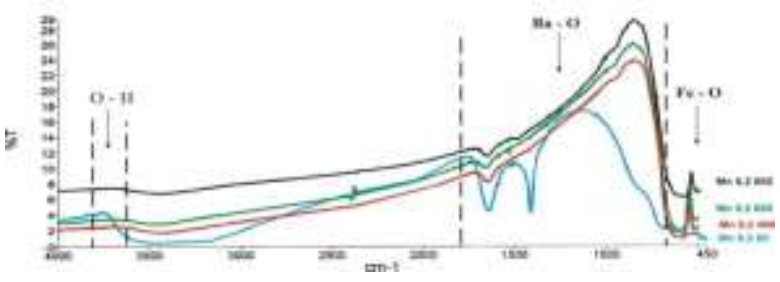

(b) $x=0,2$

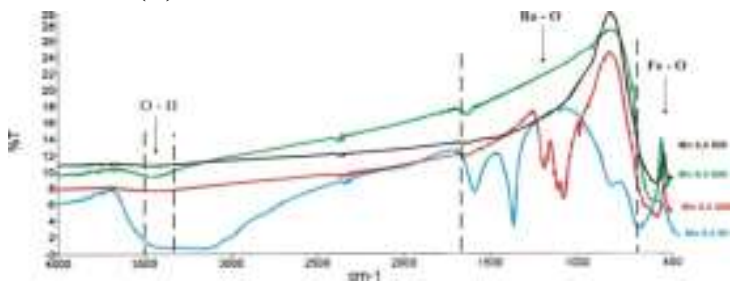

(c) $x=0,4$

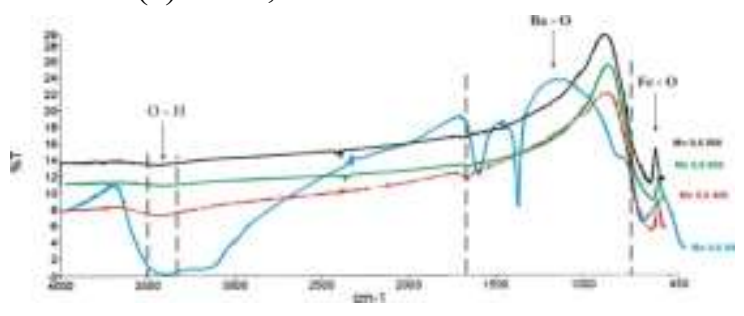

(d) $x=0,6$

Gambar 3. Hasil uji FTIR berdasarkan kesamaan variabel $\mathrm{x}$. (a) $\mathrm{x}=0$; (b) $\mathrm{x}=0,2$; (c) $\mathrm{x}=$ 0,$4 ;(d) x=0,6$.

\section{B. Pembahasan}

Berdasarkan Gambar 2 di atas, dapat dilihat bahwa semakin banyak doping yang diberikan, maka akan menghasilkan BaM dengan warna yang akan semakin gelap. Serbuk BaM tanpa doping memiliki warna yang lebih coklat yang lebih cerah dibandingkan dengan serbuk BaM yang didoping dengan logam Mn. Penambahan logam $\mathrm{Mn}$ ini nantinya diharapkan mampu meningkatkan nilai konduktivitas listrik bahan dan menurunkan nilai medan koersivitas bahan tersebut.

Setelah selesai mensintesis serbuk BaM dengan doping logam Mn, selanjutnya serbuk diuji menggunakan FTIR. Berdasarkan hasil pengujian BaM dengan doping logam Mn menggunakan FTIR yang ditunjukkan pada Gambar 2, didapatkan grafik untuk variabel yang sama namun dengan suhu yang berbeda. Meskipun suhu yang digunakan berbeda, namun semua grafik menunjukkan bilangan gelombang dengan rentang puncak antara $450 \mathrm{~cm}^{-1}$ sampai $690 \mathrm{~cm}^{-1}$ yang merupakan ikatan logam $(\mathrm{Fe}-\mathrm{O})$ pada fasa BaM. Hal ini sesuai dengan karakteristik untuk getaran yang lebih rendah dari $800 \mathrm{~cm}^{-1}$ yang dikenal sebagai ikatan logam oksigen dalam campuran. Pernyataan ini didukung oleh Durmus (2014) yang menyatakan bahwa karakteristik getaran pada rentang puncak antara $415 \mathrm{~cm}^{-1}$ sampai $570 \mathrm{~cm}^{-1}$ adalah karakteristik pada ikatan logam oksigen yang merupakan karakteristik dari barium hexaferrite ${ }^{[8]}$.

Kemudian puncak bilangan gelombang selanjutnya berada pada kisaran $1000 \mathrm{~cm}^{-1}$ sampai $1650 \mathrm{~cm}^{-1}$ menunjukkan karakteristik dari ikatan $\mathrm{BaO}$. Pernyataan senada dinyatakan oleh Pangga (2013) yang menyatakan bilangan gelombang dengan puncak antara $1000-1800 \mathrm{~cm}^{-1}$ merupakan karakteristik dari ikatan $\mathrm{BaO}$ dimana ikatan tersebut merupakan ikatan penyusun BaM. Dapat disimpulkan bahwa karateristik serapan $\mathrm{BaM}$ berada pada rentang bilangan gelombang antara 415-1800 $\mathrm{cm}^{-1}$. Karakteristik ikatan yang berada pada puncak bilangan gelombang dalam rentang antara $3000 \mathrm{~cm}^{-1}$ sampai $3500 \mathrm{~cm}^{-1}$ menunjukkan ikatan - $\mathrm{OH}$ yang keberadaannya akan hilang seiring dengan peningkatan temperatur kalsinasi ${ }^{[9]}$.

\section{PenUTUP}

Berdasarkan hasil penelitian yang telah dilakukan, dapat disimpulkan bahwa : (1) Telah berhasil dilakukan sintesis serbuk BaM dengan doping logam Mn. (2) Semakin banyak logam Mn yang ditambahkan, maka warna serbuk semakin gelap. (3) Uji FTIR dilakukan untuk menggambarkan proses terjadinya substitusi logam Mn ke dalam ikatan BaM. (4) Bilangan gelombang dengan rentang antara 450 $\mathrm{cm}^{-1}$ sampai $690 \mathrm{~cm}^{-1}$ yang merupakan ikatan logam (Fe-O) pada fasa BaM dan pada bilangan gelombang dengan kisaran rentang antara $1000 \mathrm{~cm}^{-1}$ sampai 1650 $\mathrm{cm}^{-1}$ menunjukkan karakteristik dari ikatan $\mathrm{BaO}$. (5) Karateristik serapan BaM berada pada rentang bilangan gelombang antara $415-1800 \mathrm{~cm}^{-1}$.

\section{UCAPAN TERIMA KASIH}

Ucapa terima kasih kepada semua pihak yang telah membantu sehingga terwujudnya artikel ini, dan didanai oleh hibah Penelitian Unggulan Perguruan Tinggi (PUPT) Kementerian Ristek dan Perguruan Tinggi tahun 2015. 


\section{REFERENSI}

[1] Prasongko, W.G., Priyono. 2013. Pembuatan Material Magnet Komposit $\mathrm{BaFe}_{9} \mathrm{Mn}_{0,75} \mathrm{Co}_{0,75} \mathrm{Ti}_{1,5} \mathrm{O}_{19}$ /Elastomer untuk Aplikasi Penyerap Gelombang Elektromagnetik. Universitas Diponegoro : Semarang

[2] Narang, S., Hudiara, I.S. and Bai, Y. (2006) The Effect of Co and Zr Substitution on dc Magnetic Properties of Ba-Sr Ferrite. Journal of Alloys and Compounds, 464, 429-433.

[3] Mallick, K.K., Shepherd, P., Green, R.J. 2007. Magnetic properties of cobalt substituted M-type barium hexaferrite prepared by co-precipitation. Journal of Magnetism and Magnetic Materials 312. Hal. 418-429.

[4] Ahmeda, Okashab, Kershi. 2008. Influence of Rare-earth Ions on The Structure and Magnetic Properties of Barium W-type Hexaferrite. Journal of Magnetism and Magnetic Materials 320, hal. 1146-1150.

[5] Hahn, D. W., Han, Y. H. 2006. C02Z Type Hexagonal Ferrites Prepared by Sol-gel Method., Materials Chemistry and Physics, Vol.95, hal. 248-251.
[6] Priyono, Ahyani, M. 2010. Sintesis Barium Hexaferrite Yang Disubstitusi Ion Mn-Co Melalui Reaksi Padat Dan Pengaruhnya Terhadap Perubahan Struktur Dan Sifat Magnet.Jurnal Sains dan Matematika. Hal. 146-150.

[7] Susilawati dan Doyan, A. 2013. Sintesis dan Studi Pendahulan Struktur Bahan Hexaferrite Untuk Aplikasi Anti Radar. Proseding Seminar Nasional Penelitian, Pembelajaran Sains Dan Implementasi Kurikulum 2013. Program Studi Magister Pendidikan IPA Program Pascasarjana Universitas Mataram : Mataram

[8] Durmus, Z. 2014. Synthesis, conductivity and dielectric characterization of salicylic acid- $\mathrm{Fe}_{3} \mathrm{O}_{4}$ nanocomposite. Royal Institute of Technology : Stockholm, Sweden

[9] Pangga, D. 2011. Pengaruh substitusi Ion Dopan Co/Zn Terhadap Struktur Kristal Barium MHeksaferit $\left(\mathrm{BaFe}_{12} \mathrm{O}_{19}\right)$. Institut Teknologi Sepuluh Nopember : Surabaya 